\title{
BRAIN SIZE OF THE AFRICAN GRASSCUTTER (Thryonomys swinderianus, TEMMINCK, 1827) AT DEFINED POSTNATAL PERIODS
}

\author{
Ibe, C. S. ${ }^{1}$, Salami, S. O. ${ }^{2}$, Wanmi, N. ${ }^{3}$ \\ ${ }^{1}$ Department of Veterinary Anatomy, Michael Okpara University of Agriculture, Umudike \\ ${ }^{2}$ University of Ilorin, Ilorin \\ ${ }^{3}$ University of Agriculture, Markurdi \\ Nigeria
}

writechikera@yahoo.com

\section{ABSTRACT}

As a sequel to the current advancement in ethology, this study was designed to provide information on the brain size of the African grasscutter at specific postnatal periods and to extrapolate these findings to the behaviour of the rodent in its natural habitat. Brain samples were extracted from African grasscutter neonates on postnatal day 6 , juveniles on postnatal day 72 and adults on postnatal day 450 by basic neuro-anatomical techniques. The weight, volume and dimensions of the brain samples were determined in absolute and relative terms. Their encephalisation quotient was also computed. There was a very strong positive correlation between nose-rump length and brain length in the neonates. The relative brain weight of neonates, juveniles and adults were $3.84 \pm 0.12 \%, 2.49 \pm 0.07 \%$ and $0.44 \pm 0.03 \%$, respectively. The differences were significant $(\mathrm{P}<0.05)$. The encephalisation quotient of juveniles was $1.62 \pm 0.03$ while that of the adult was $0.49 \pm 0.02$. The difference was significant $(\mathrm{P}<0.05)$. The results were extrapolated to the animal's cognitive ability, and compared with other rodents. It was concluded that the juvenile African grasscutter may have higher cognitive ability than the adult rodent, thus, juveniles should be preferred in physiological studies of memory and cognition.

Key words: African grasscutter; brain; cognition; Encephalisation Quotient

\section{INTRODUCTION}

The qualification of intelligence in animals does not have a specific yard-stick. It can be explained as the extent to which an animal is able to acquire cues to solve complex problems posed by the environment including interspecies communication, threat detection and response. Simont on [30] stated that intelligence is a set of cognitive capacities such as memory and retrieval or problem solving that enable an individual to adapt and thrive in any given environment. Deary [6] proposed that the environment and its interaction with genes play a vital role with regards to cognition. However, as environmental challenges vary 
with animals of the same class, the measure of cognition may not be taxa-specific, but closely related to the animal's environment. In their review, Roth and Dicke [28] explained that cognition is not orthogenetic but has evolved independently in different classes of vertebrates, such that in each class, some animals are considered most intelligent. For example, parrots and owls are considered most intelligent in avian class [15] and primates in mammalian [16].

Brain size is a measure of its dimension, volume and weight. It varies with species, breed, sex and age. According to Sahin et al. [29], changes in brain size are due to changes in the number of neuronal and neuroglial cells in the brain, which is dependent on the extent or rate of neurogenesis. There is a fierce debate on the relationship between brain size and cognition. While some authors [18, 21] agree to a strong correlation between the two, others [8, 32] emphasize that the neuronal connectivity and internal complexity of the neuronal network defines cognition, and not just the size of the brain. The debatable brain markers for cognitive ability are the absolute or relative size of the brain, cortical gray matter thickness, encephalisation quotient and cortical neurone number [9, 18, 21, 28,]. However, encephalisation quotient and cortical neurone number are more reliable markers than absolute or relative brain size. Rieke [27] attributed encephalisation quotient as a rough estimate of the cognitive ability of an animal. Her culano-Houzel [9] observed that more encephalised rodents have larger number of neurones than expected for their body size, and proposed that the excess neurones may be responsible for the improved associative functions and cognitive advantage observed in them.

Encephalisation quotient is a useful measure which provides the information of how much bigger or smaller an animal's brain is, after the effect of body size has been corrected. Encephalisation quotient was developed for mammals, and may not yield relevant results when applied to non-mammals [20]. It is hypothesized to be a rough estimate of the intelligence of an animal [27], and varies among animals of even the same genus. No wonder Krubitzer et al. [14] reported that encephalisation quotient of tree squirrels is higher than that of ground squirrels and attributed it to the need for a higher cognitive ability for climbing.

The subject is a rodent of the sub-order Hystricomorpha. The family (Thryonomyidae) is represented by a single genus, Thryonomys; and two species, Thryonomys swin- derianus, known as the greater cane rat and Thryonomys gregorianus, known as the lesser cane rat [4]. The generic name Thryonomys was coiled from the Greek word "thryon" which means reed and "mys" which means mouse. They are known to rapidly destroy reeds with their incisors [2]. Thus, the name cane rat, due to their destructive effects on sugar-cane plantations, and their preference for cane grass (Eragrostis infecunda). The rodent is found in virtually all African countries, including Nigeria [31]. They reside in grassland or in wooded savannah, along riverbanks [3]. They are rare in the arid Horn of Africa [23]. They are not common in rainforest, and do not inhabit dry shrub or desert [19]. Genetically, they are more closely related to the porcupine than to the house rat [19].

Over time, researchers have compared the cognitive ability of adult rodents of different species [5, 9, 10]; no attention is geared towards depicting the variation in the cognitive ability of rodents of same species, but of different ages. It may be a general notion that adult animals are more intelligent than juveniles and neonates, but, a recent neuro-anatomical study [22] has shown that juvenile animals may have higher cognitive potentials than their adult counterparts.

To determine the cognitive ability of different age groups of the African grasscutter, the brain sizes were determined and compared in the present study.

\section{MATERIALS AND METHODS}

\section{Experimental Animals and Management}

A total of 27 apparently healthy African grasscutters, comprising of 9 neonates of 6 days old, 9 juveniles of 72 days old and 9 adults of 450 days old were used for the study. They were purchased from a commercial grasscutter farm in Elele, Rivers state, Nigeria. The ages of the animals were confirmed from the farm records. There were transported by road in locally made wooden cages with adequate ventilation, and measuring $1.5 \mathrm{~m} \times 1.5 \mathrm{~m} \times 1.5 \mathrm{~m}$, to the Veterinary Histology Laboratory of the Michael Okpara University of Agriculture, Umudike, Abia state, Nigeria, for the study. In the laboratory, there were transferred to standard laboratory animal cages and kept for a pre-experimental period of 1 month. They were fed twice daily, $8.00 \mathrm{a}$. m. and 6.00 p.m. They were fed with fresh guinea grass (Panicum maximum), fresh cane grass (Eragrostis infecunda) and 
commercial rodent pelleted concentrates. Drinking water was provided ad libitum. The feeding troughs and drinkers were sterilized daily using Milton ${ }^{\circledR}$ (Laboratoire Rivadis, Louzy, France; active ingredient: sodium hypochlorite $2 \% \mathrm{w} / \mathrm{w})$. The cages were also swept and disinfected daily using Milton ${ }^{\oplus}$, as well as a broad spectrum bactericidal, fungicidal and veridical agents.

The experimental protocol was approved by the Ethical Committee of Ahmadu Bello University, Zaria, Nigeria. The management of the experimental animals was as stipulated in the Guide for the Care and Use of Laboratory Animals, 8th Edition, National Research Council, USA (National Academic Press, Washington D.C.: www.nap.edu.).

\section{Brain Extraction}

Each animal was sedated by an intraperitoneal injection of $20 \mathrm{mg} \cdot \mathrm{kg}^{-1}$ thiopental sodium (Rotexmedica, Trittau, Germany) and immediately weighed using a digital electronic balance [Citizen Scales (1) PVT Ltd., sensitivity: $0.01 \mathrm{~kg}$ ] and converted into grams. The nose-rump and tail lengths were also obtained with a centimetre measuring tape and converted into millimetres. The anogenital distance was obtained using a vernier caliper MG6001DC (General Tools and Instruments Co., New York; sensitivity of $0.01 \mathrm{~cm}$ ) and converted to millimetres. Thereafter, each animal was placed on a dorsal recumbency on a dissection table, and perfused with $4 \%$ paraformaldehyde fixative, through the left ventricle, using a modification of the method of Gage et al. [7]. Immediately after the perfusion fixation, the head was separated from the rest of the body at the atlanto-occipital joint, using a pair of scissors and knife. Thereafter, each skull containing the brain was obtained after skinning and stripping off all the facial muscles; then, craniotomy preceded the brain extraction. Specifically, brain extraction was performed in a caudo-rostral and dorso-ventral direction, using scalpel blades, thumb forceps, rongeur and a pair of scissors. The meninges and underlying blood vessels were gently removed to expose the intact brain.

\section{Determination of Brain Size}

The absolute brain weight was obtained using the Mettler balance P 1261 (Mettler instrument AG., Greifensee, Switzerland; sensitivity: $0.01 \mathrm{~g}$ ). The absolute brain length was obtained using a vernier caliper MG6001DC (General Tools and Instruments Co., New York; sensitivity of
$0.01 \mathrm{~cm})$ and then converted into millimetres. The landmark for the absolute brain length was the rostro-caudal extent of the intact brain, from the tip of the olfactory bulb to the caudal end of the medulla oblongata. The volume measurement was obtained by the water displacement method. Each brain specimen was totally submerged into a known volume of bi-distilled water at $20^{\circ} \mathrm{C}$ in a graduated cylinder. The volume difference in the cylinder equalled the brain volume in millilitres. The relative brain weight was calculated by dividing the absolute brain weight by the body weight, expressed in percentages. The relative brain length was calculated by dividing the absolute brain length by the nose-rump length, expressed in percentages. The encephalisation quotient was calculated using the formula of Martin [17] for the expected brain mass as shown below:

$$
\mathrm{EQ}=\frac{\text { Mbrain }}{0.059 \text { Mbody }^{0.76} \text { (Martin's formula for expected brain mass) }}
$$

Where

$\mathrm{EQ}=$ Encephalisation quotient

Mbrain = Absolute brain weight $[\mathrm{g}]$

Mbody = Body weight $[\mathrm{g}]$

\section{Statistical Analysis}

Data obtained for each postnatal period was expressed as the mean \pm SEM (Standard Error of the Mean) and presented in tables and graphs. The values were subjected to one-way analysis of variance (ANOVA), followed by Turkey's post-hoc test to determine the significance of the mean. The association between the values of the body weight with brain weight, and nose-rump length with brain length, were determined using Pearson's coefficient of correlation, at the $95 \%$ confidence interval. The values of $\mathrm{P}<0.05$ were considered significant. GraphPad Prisms, version 4 for Windows 8 was used for the statistical analysis.

\section{RESULTS}

The mean body weights of the African grasscutters on postnatal days 6,72 and 450 were $160.11 \pm 7.46 \mathrm{~g}$, $273.39 \pm 6.70 \mathrm{~g}$ and $2925.56 \pm 141.96 \mathrm{~g}$, respectively, while the mean nose-rump lengths were $182.00 \pm 3.87 \mathrm{~mm}$, $216.89 \pm 5.18 \mathrm{~mm}$ and $470.33 \pm 8.47 \mathrm{~mm}$, respectively. The mean tail lengths were $70.67 \pm 0.96 \mathrm{~mm}, 84.78 \pm 1.58 \mathrm{~mm}$ and $173.32 \pm 7.92 \mathrm{~mm}$, respectively, while the mean ano- 
genital distances were $14.01 \pm 0.20 \mathrm{~mm}, 16.69 \pm 0.18 \mathrm{~mm}$ and $34.59 \pm 1.17 \mathrm{~mm}$, respectively.

The mean brain weight, length and volume of each of the postnatal periods are presented in Table 1. The morphometric indices of the whole brain adopted for brain size comparison at the different postnatal periods included the relative brain weight, relative brain length and encephalisation quotient. The decrease in relative brain weight across the different postnatal periods was consistent and statistically significant $(\mathrm{P}<0.05)$, such that, while the value on postnatal day 6 was $3.32 \pm 0.19 \%$, the value on postnatal day 450 was $0.44 \pm 0.03 \%$ (Table 2 ). There was a consistent decrease in encephalisation quotient across the different postnatal periods; there was a significant $(\mathrm{P}<0.05)$ decrease in the encephalisation quotient from juvenile to adulthood in the African grasscutter. The relative brain length of the animals on postnatal day 450 was $13.59 \pm 0.42 \%$ (Table 2 ). The value was significantly $(\mathrm{P}<0.05)$ higher than corresponding values obtained on postnatal days 6 and 72 .
There was a very strong positive correlation $(r=0.85$; $\mathrm{P}<0.01$ ) between nose-rump length and brain length on postnatal day 6 . This implies that as at day 6 post-partum, the brain length of the African grasscutter increased at approximately the same rate with the nose-rump length. The positive correlation result was subjected to regression analysis, and a regression formula was deduced on a graph (Fig. 1) as follows:

$$
y=0.132 x+18.00
$$

where

$y=$ brain length; $x=$ known nose-rump length.

Thus, for a 6-day-old African grasscutter whose noserump length is obtained $(\mathrm{x})$, the approximate length of the brain (y) can be deduced from the above formula. This formula offers the advantage of obtaining the approximate brain length in a 6-day-old African grasscutter.

Table 1. Brain morphometric parameters in the African grasscutter at different postnatal periods

\begin{tabular}{lcccc}
\hline \multicolumn{1}{c}{ Parameter } & Postnatal period & Minimum & Maximum & Mean ( \pm SEM) \\
\hline \multirow{4}{*}{$\begin{array}{l}\text { Absolute brain weight } \\
{[\mathrm{g}]}\end{array}$} & Day 6 & 4.73 & 5.62 & $5.21 \pm 0.15$ \\
& Day 72 & 6.65 & 7.00 & $6.77 \pm 0.04$ \\
& Day 450 & 11.35 & 13.00 & $12.22 \pm 0.23$ \\
\hline $\begin{array}{l}\text { Absolute brain length } \\
{[\mathrm{mm}]}\end{array}$ & Day 6 & 41.00 & 43.00 & $41.91 \pm 0.26$ \\
& Day 72 & 50.90 & 55.00 & $53.18 \pm 0.52$ \\
\hline & Day 450 & 60.10 & 70.00 & $63.74 \pm 1.47$ \\
$\begin{array}{l}\text { Brain volume } \\
{[\mathrm{ml}]}\end{array}$ & Day 6 & 5.32 & 6.91 & $5.91 \pm 0.22$ \\
& Day 72 & 8.91 & 9.92 & $9.41 \pm 0.11$ \\
\hline
\end{tabular}

Table 2. Mean ( \pm SEM) value of brain size indices of the African grasscutter at different postnatal periods abcd $=$ means in rows with different superscripts are significantly $(P<0.05)$ different

\begin{tabular}{lccc}
\hline \multicolumn{1}{c}{ Brain parameter } & Day 6 & Postnatal period & Day 450 \\
\cline { 2 - 4 } & $3.32 \pm 0.19^{\mathrm{a}}$ & $2.49 \pm 0.07^{\mathrm{b}}$ & $0.44 \pm 0.03^{\mathrm{c}}$ \\
\hline $\begin{array}{l}\text { Relative brain weight } \\
{[\%]}\end{array}$ & $1.89 \pm 0.09^{\mathrm{a}}$ & $1.62 \pm 0.03^{\mathrm{b}}$ & $0.49 \pm 0.02^{\mathrm{c}}$ \\
$\begin{array}{l}\text { Encephalisation quotient } \\
\begin{array}{l}\text { Relative brain length } \\
{[\%]}\end{array}\end{array}$ & $23.03 \pm 0.19^{\mathrm{a}}$ & $24.63 \pm 0.62^{\mathrm{a}}$ & $13.59 \pm 0.42^{\mathrm{b}}$ \\
\hline
\end{tabular}




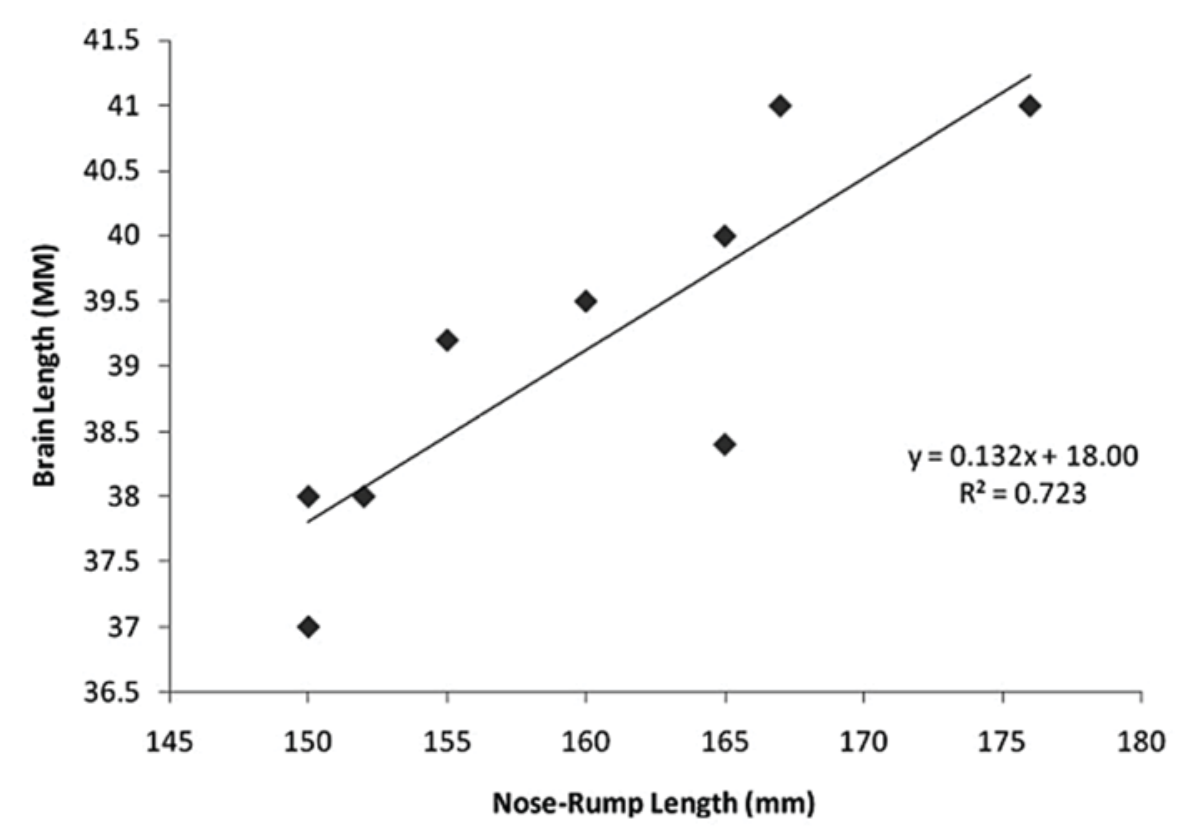

Fig. 1. Positive linear relationship between nose-rump length and brain length of the African grasscutter on postnatal day 6

\section{DISCUSSION}

The neonatal period varies between species. In humans, it is generally accepted as the time elapsed between birth and 28 days of age. As the African grasscutter has a lower life expectancy than humans; in the present study, animals of 3- and 6-day old were classified as neonates. Similarly, as juvenile refers to an immature individual, the animals of 72 days' old were grouped as juveniles. This is in tandem with the grouping presented by A sibey and Ado [3] in which African grasscutters with two sets of cheek teeth (1 set of premolar and 1 set of molar) were classified as juveniles. Adu and Yeboah [1] confirmed that the African grasscutter reaches sexual maturity at 7 months, when the female attains about $2 \mathrm{~kg}$ body weight. Thus, animals that have attained sexual maturity and above $2 \mathrm{~kg}$ body weight, aged 450 days and above, were classified and used as adults.

To determine the level of intelligence of the different postnatal age groups of the African grasscutter, the encephalisation quotient of each postnatal group was computed using the formula of Martin [17], an improvement on the formula of Jeris on [12]. The result of the encephalisation quotient in the present study points to a higher memory and cognition in the neonate and juvenile African grasscutters, compared to the adults. Similarly, in their study of postnatal neurogenesis, Olude et al. [22] reported a high level of plasticity in the juvenile African giant pouched rat, suggested the best learning abilities in the group; thus, proposed the juvenile rats as the most suited for experimental research. The fact that neurones are lost via apoptosis during neurogenesis as the animal advanced in age may be the reason for a lower encephalisation quotient in adult than juvenile or neonatal African grasscutters. Ageing has also been known to pose some detrimental effects on brain cells, gross morphology of the brain and cognition [26]. Most physiological studies of memory and cognition make use of adult rodents. Based on the result of the present study, neonates or at least juvenile rodents may be preferred to adults, for memory and cognition related studies. This does not underscore the assumption that larger rodents such as the adult African grasscutter or the adult African giant pouched rat may be better models for electrophysiological studies as they have absolutely larger neurones that can easily be used for intracellular electrode recordings than smaller-sized rodents like the Wistar rat.

The absence of a significant difference in the relative brain weight of the neonate and juvenile, but the presence of a significant difference in the encephalisation quotient further demonstrates that encephalisation quotient is a more sensitive marker than relative brain weight as it takes into account allometric effects. Mo ore [20] observed that expression of brain size among different species, based on 
their encephalisation quotient, provided a ranking of animals that coincided better with observed complexity of behaviour than that provided due to brain size, based on the relative brain weight. The encephalisation quotient of the adult African grasscutter was lower than the 1.19 reported for the adult African crested porcupine (Hystrix cristata) by Papini [25]. Both animals (African grasscutter and African crested porcupine) are large rodents, belonging to the same sub-order Hystricomorpha. The marked difference in their encephalisation quotient further tests the hypothesis that cognitive ability in animals is not taxa-specific. The difference in encephalisation quotient of the two animals may be due to their varied habitats, and that high cognitive ability is required to solve challenging ecological problem of predator evasion posed to the African crested porcupine. Similarly, Krubitzer et al. [14] reported that the encephalisation quotient of tree squirrels was higher than that of ground squirrels, as higher cognition was needed in the tree climbing squirrels.

The encephalisation quotient of adult African grasscutter recorded in the present study is almost the same as the value of 0.40 reported for adult African grasscutter, but higher than 0.19 reported for adult African giant pouched rat by Byanet and Dzenda [5]. This finding may indicate higher cognitive abilities in the adult African grasscutter than in the adult African giant pouched rat, partly due to their varied habitats. The African giant pouched rat is adapted to solitary life in burrows [10], with less exposure to predation; the African grasscutter lives on grassland, and therefore relatively more exposed to predation than the African giant pouched rat.

The relative brain length of the adult African grasscutter from the present study was higher than the value of $10.76 \%$ reported for the adult African giant pouched rat [11], but less than the $15 \%$ reported for the adult squirrel [13]. The differences are due to species variations, and may be extrapolated to their varied cognitive abilities. The brain length of the adult African grasscutter from the present study is comparable to the cranial length of $7.89 \mathrm{~cm}$ obtained for the adult African grasscutter by Onwuama et al. [24]. The higher cranial length than brain length is expected owing to the space occupied by the cranial meninges. There is a need for further research to determine if a very strong correlation exists between head length and brain length, so as to obtain a formula that can be used to estimate brain length of the African grasscutter without sacrificing the animal. The regression formula obtained from the very strong positive correlation between noserump length and brain length in 6-day-old neonates is important as it can be applied in estimating brain length of live African grasscutter neonates of 6 days' old, by measuring their nose-rump length.

\section{CONCLUSIONS}

The present study has provided information on the brain size of the African grasscutter, and related the finding to the behaviour of the animal. It has explained the need to prefer the use of juveniles to adult rodents as models for physiological studies of memory and cognition. It has generated a regression formula that can be used to estimate the brain length of a live African grasscutter neonate of 6 days' old. The results of the present study, which has added to existing information on the neurobiology of the rodent, will serve as a lead for future cognitive studies involving the African grasscutter.

\section{REFERENCES}

1. Adu, E. K., Yeboah, S., 2000: The efficacy of the vaginal plug formation after mating for pregnancy diagnosis and embryonic resorption in utero in the greater cane rat (Thryonomys swinderianus, Temminck). J. Trop. Anim. Health Prod., 32, $1-10$.

2. Amori, G., Gippoliti, S., 2002: Rodents and the bushmeat harvest in Central Africa. In Mainka, S., Trivedi, M.: Links between Biodiversity Conservation, Livelihoods and Food Security. The Sustainable Use of Wild Species for Meat. IUCN Species Survival Commission, 24, 95-100.

3. Asibey, E. O.A., Addo, P. G., 2000: The grasscutter, a promising animal for meat production. In Turnham, D.: African Perspectives. Practices and Policies Supporting Sustainable Development. Scandinavian Seminar College, Denmark, in association with Weaver Press, Harare, Zimbabwe, 120 pp.

4. Bronner, G. N., Hoffmann, M., Taylor, P.J., Chimimba, C. T., Best, P., Matthee, C.A., Robinson, T.J., 2003: A revised systematic checklist of the extant mammals of the southern African subregion. Durban Mus. Novit., 28, 56-95.

5. Byanet, O., Dzenda, T., 2014: Quantitative biometry of body and brain in the Grasscutter (Thryonomys swinderianus) and 
African giant rat (Cricetomys gambianus): encephalization quotient implication. Res. Neurosci., 3, 1-6.

6. Deary, I. J., 2000: Looking Down on Human Intelligence: from Psychometrics to the Human brain. Oxford: Oxford University Press, DOI:10.1093/acprof:oso/9780198524175.001.0001.

7. Gage, G. J., Kipke, D. R., Shan, W., 2012: Whole animal perfusion fixation for rodents. JVE, 65, e3564.

8. Gläscher, J., Rudrauf, D., Colom, R., Paul, L.K., Tranel, D., Damasio, H., Adolphs, R., 2010: Distributed neural system for general intelligence revealed by regional mapping. In Proceedings of the National Academy of Sciences of the United States of America, doi: 10.1073/pnas/ /0910397107.

9. Herculano-Houzel, S., 2007: Encephalization, neuronal excess and neuronal index in rodents. Anat. Rec., 290, 128-1287.

10. Ibe, C. S., Onyeanusi, B. I., Hambolu, J. O., 2014: Functional morphology of the brain of the African giant pouched rat (Cricetomys gambianus, Waterhouse, 1840). Onderstepoort J. Vet. Res., 81, 7. http://dx.doi.org/10.4102/ojvr.v81i1.644.

11. Ibe, C. S., Onyeanusi, B. I., Hambolu, J. O., Ayo, J. O., 2010: Sexual dimorphism in the whole brain and brainstem morphometry in the African giant pouched rat (Cricetomys gambianus, Waterhouse 1840). Folia Morphol., 69, 69-74.

12. Jerison, H. J., 1977: The theory of encephalisation. Ann. N. Y. Acad. Sci., 299, 146-160.

13. Kinser, P. A., 2000: Chart of Approximate Brain and Body Sizes of Various Animals. In http://serendip.brynmawr.edu/bb/kinser/Sizechart.html. Accessed: 07/09/2015. 17:44:23 GMT.

14. 14. Krubitzer, L., Campi, K.L., Cooke, D. F., 2011: All rodents are not the same: a modern synthesis of cortical organization. Brain Behav. Evol., 78, 51-93.

15. Lefebvre, L., Reader, S. M., Sol, D., 2004: Brains, innovations and evolution in birds and primates. Brain Behav. Evol., 63, $233-246$

16. Marino, L., 2002: Convergence of complex cognitive abilities in cetaceans and primates. Brain Behav. Evol., 59, 21-32.

17. Martin, R.D., 1984: Body size, brain size and feeding strategies. In Chivers, D., Wood, B., Bilsborough, A.: Food Acquisition and Processing in Primates. Plenum Press, New York, 73-103.

18. McDaniel, M.A., 2005: Big-brained people are smarter: A meta-analysis of the relationship between in vivo brain volume and intelligence. Intelligence, 33, 337-346.

19. Mensah, G. A., Okeyo, A. M., 2005: Continued harvest of the diverse African animal genetic resources from the wild through domestication as a strategy for sustainable use: A case of the larger grasscutter: Thryonomys swinderianus. In http://agtr.ilri. cgiar.org/index.php?option $=$ com_content\&task $=$ view\&id $=177$ \&Itemid=199. Accessed: 27/10/2012, 23: 12: 34 GMT.

20. Moore, J., 1999: Allometry. University of California, San Diego. In http://pages.ucsd.edu/ jmoore/courses/allometry/allometry.html. Accessed: 02/10/2017, 01: 45: 23 GMT.

21. Narr, K. L., Woods, R. P., Thompson, P. M., Szeszko, P., Robinson, D., Dimtcheva, T. et al., 2007: Relationships between IQ and regional cortical gray matter thickness in healthy adults. Cereb. Cortex, 17, 2163-2171.

22. Olude, A.M., Olopade, J.O., Ihunwo, A.O., 2014: Adult neurogenesis in the African giant rat (Cricetomys gambianus, Waterhouse). Metabol. Brain Dis., 29, 857-866.

23. Onebunne, A., 2010: Grasscutter Farming - the Pathway to Wealth. In http://grasscutterfarmingbest.blogspot.com. Accessed: 16:08:2014. 16:07:27 GMT.

24. Onwuama, K. T., Ojo, S. A., Hambolu, J. O., Salami, O.S., Dzenda, T., 2014: Gross-anatomical and morphometric studies of the grasscutter (Thryonomys swinderianus), axial skeleton. Stand. Sci. Res. Ess., 2, 406-417.

25. Papini, M. R., 2008: Evolution of the vertebrate brain and behaviour. In Comparative Psychology: Evolution and Development of Behaviour. 2nd edn., Psychology press, 270 Madison Avenue, New York, 273-277.

26. Peters, R., 2006: Ageing and the brain. Postgrad. Med. J., 2006, 82, 84-88.

27. Rieke, G., 2011: Lecture notes: Emergence of intelligence. Natural Sciences, 102, University of Arizona.

28. Roth, G., Dicke, U., 2005: Evolution of the brain and intelligence. Trends in Cognitive Sciences, 9, 250-257.

29. Sahin, B., Aslan, H., Unal, B., Canan, S., Bilgig, S., Kaplan, S., Tumkaya, L., 2001: Brain volumes of the lamb, rat and birds do not show hemispheric asymmetry: A stereological study. Image Anal. Stereol., 20, 9-13.

30. Simonton, D.K., 2003: An interview with Dr. Simonton. In Plucker, J. A.: Human Intelligence: Historical Influences, Current Controversies, Teaching Resources. Accessed online from http:// indiana.edu/_intell. Accessed: 21/04/2014; 04:23:31 GMT.

31. Van der Merwe, M., 2007: Discriminating between Thryonomys swinderianus and Thryonomys gregorianus. African Zoology, 42, 165-171.

32. Zilles, K., Palomero-Gallagher, N., Amunts, K., 2013: Development of cortical folding during evolution and ontogeny. Trends Neurosci., 36, 75-284.

Received July 14, 2017

Accepted August 23, 2017 